\title{
Pengaruh Jenis dan Volumetrik Fiber terhadap Kekuatan Transversal Reparasi Plat Resin Akrilik
}

\author{
Pramudya Aditama*, Siti Sunarintyas ${ }^{* *}$, dan Widjijono** \\ *Bagian Prostodonsia, Fakultas Kedokteran Gigi, Universitas Gadjah Mada, Yogyakarta, Indonesia \\ **Bagian Biomaterial, Fakultas Kedokteran Gigi, Universitas Gadjah Mada, Yogyakarta, Indonesia \\ *JI Denta No 1, Sekip Utara, Yogyakarta, Indonesia; e-mail: pramudyaaditama@ugm.ac.id
}

\begin{abstract}
ABSTRAK
Resin akrilik merupakan bahan yang sering digunakan dalam pembuatan basis gigi tiruan. Kelemahan resin akrilik adalah mudah patah. Salah satu cara untuk mengatasi masalah tersebut adalah dengan menambahkan polyethylene (PE) atau glass fiber. Tujuan dari penelitian ini untuk mengetahui pengaruh jenis dan volumetrik fiber terhadap kekuatan transversal reparasi plat resin akrilik. Penelitian ini menggunakan dua puluh lima plat resin akrilik kuring panas berukuran $65 \times 10 \times$ $2,5 \mathrm{~mm}$. Subjek dipreparasi untuk membuat jarak $3 \mathrm{~mm}$ dan sudut bevel $45^{\circ}$. Subjek dibagi menjadi 5 kelompok, masingmasing kelompok terdiri dari 5 subjek. Kelompok 1 (kontrol) tanpa penambahan fiber, kelompok II dengan penambahan $3,7 \%$ v/v PE fiber, kelompok III dengan penambahan $7,4 \%$ v/v PE fiber, kelompok IV dengan penambahan $3,7 \%$ v/v E-glass fiber, dan kelompok $V$ dengan penambahan $7,4 \%$ v/v E-glass fiber. Seluruh plat direndam dalam air destilasi selama satu hari pada suhu $37^{\circ} \mathrm{C}$. Pengujian kekuatan transversal plat resin akrilik dengan menggunakan Universal Testing Machine dan data yang didapat dianalisis menggunakan ANAVA dua jalur dengan tingkat kepercayaan $95 \%$. Rerata kekuatan transversal (MPa) reparasi plat resin akrilik yang diperkuat fiber: $3,7 \%$ v/v PE fiber $(67,77 \pm 3,34) ; 7,4 \%$

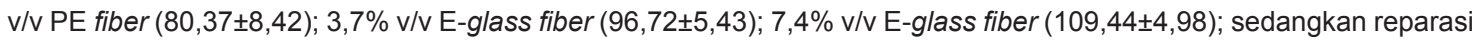
plat resin yang tidak diperkuat fiber menghasilkan kekuatan transversal $56,27 \pm 4,7 \mathrm{MPa}$. Hasil analisis menggunakan ANAVA dua jalur menunjukkan variabel jenis dan volumetrik fiber memberikan pengaruh signifikan $(p<0,05)$, sedangkan interaksi antara jenis dan volumetrik fiber tidak berpengaruh signifikan $(p>0,05)$. Uji post hoc Tukey menunjukkan perbedaan signifikan $(p<0,05)$ untuk seluruh kelompok perlakuan. Penambahan E-glass fiber dalam reparasi plat resin akrilik mampu meningkatkan kekuatan transversal lebih tinggi dibandingkan dengan menggunakan PE fiber. Peningkatan volumetrik fiber dapat meningkatkan kekuatan transversal reparasi plat resin akrilik.
\end{abstract}

Maj Ked Gi Ind. Juni 2015; 1(1): hal 102-108

Kata Kunci: E-glass fiber, polyethylene fiber, volumetrik fiber, kekuatan transversal, reparasi akrilik

\begin{abstract}
Effect Of Type And Volumetric Fiber On Transverse Strength Of Acrylic Resin Plate Repair. Acrylic resin is the most common denture base material. A disadvantage of acrylic resin is that it is easily fractured. One way to resolve this problem is by adding polyethylene (PE) or glass fibers. The purpose of this research is to find out about the effect of type and volumetric fiber on transverse strength of acrylic resin plate repaired. The experiment involved twenty five plates of heat cured acrylic with the dimensions of $65 \times 10 \times 2.5 \mathrm{~mm}$. The speciments were prepared to create a $3 \mathrm{~mm}$ gap and $45^{\circ}$ bevel. The subjects were divided into 5 groups; each group consisted of 5 . Group I (control) was without fiber reinforcement, group II reinforced with 3.7\% v/V PE fiber, group III reinforced with $7.4 \%$ V/V PE fiber, group IV reinforced with $3.7 \% \mathrm{~V} / \mathrm{V}$ E-glass fiber, and group $\mathrm{V}$ reinforced with $7.4 \% \mathrm{~V} / \mathrm{V}$ E-glass fiber. All plates were soaked in distilled water for one day at $37^{\circ} \mathrm{C}$ temperature. The plates were tested for transverse strength with Universal Testing Machine and all data obtained were analyzed with two way ANOVA at 95\% confidence level. The mean of transverse strength (MPa) of

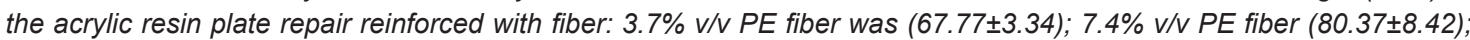

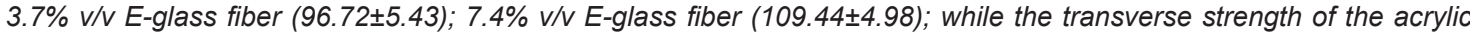
resin plate with no fiber reinforced was $56.27 \pm 4.7 \mathrm{MPa}$. Two way ANOVA analysis shows that type and volumetric fiber had significant effect $(p<0.05)$, while the interaction between type and volumetric fiber had no significant effect $(p>0.05)$. Tukey post hoc test shows significant difference $(p<0.05)$ for all groups. The addition of E-glass fibers in the acrylic resin plate repaired increased the transverse strength higher than that with PE fibers. The increase in volumetric fibers might improve the transverse strength of the acrylic resin plate repaired.

Maj Ked Gi Ind. Juni 2015; 1(1): hal 102-108
\end{abstract}

Keywords: E-glass fiber, polyethylene fiber, volumetric fiber, transverse strength, acrylic repair

\section{PENDAHULUAN}

Pada tahun 2007, jumlah pengguna gigi tiruan di Indonesia mencapai $4,5 \%$ dari jumlah penduduk dan mayoritas digunakan oleh penduduk yang berusia di atas 65 tahun. Gigi tiruan yang paling banyak digunakan adalah jenis gigi tiruan lepasan. ${ }^{1}$ 
Resin akrilik masih menjadi bahan pilihan dalam pembuatan plat gigi tiruan karena harganya relatif murah, mudah direparasi, proses pembuatannya mudah dan menggunakan peralatan sederhana, serta memiliki warna stabil dan mudah dipoles. ${ }^{2}$ Masalah yang sering dijumpai pada pemakai gigi tiruan lepasan berbahan resin akrilik adalah fraktur atau patahnya plat gigi tiruan yang disebabkan oleh tekanan oklusal yang besar. $^{3}$

Beberapa upaya untuk meningkatkan kekuatan reparasi plat gigi tiruan resin akrilik telah dilakukan, seperti modifikasi pada bahan plat gigi tiruan atau dengan menambahkan fiber. ${ }^{4}$ Penggunaan fiber dalam resin akrilik telah dikembangkan secara luas. Hal ini dikarenakan fiber memiliki karakteristik antara lain: dapat meningkatkan sifat fisik dan mekanik resin akrilik, dapat meningkatkan kekuatan plat resin akrilik, bentuk fiber yang mudah digunakan, mudah dalam pengaturannya, dan memiliki sifat estetik yang baik. ${ }^{5}$

Polyethylene fiber terbuat dari pintalan gel fiber dengan kristalinitas yang sangat tinggi sekitar $95 \%$ $99 \% .^{6}$ Glass plasma dingin pada polyethylene fiber mampu meningkatkan reaktifitas dan kemampuan wetting pada fiber sehingga dapat menghasilkan interaksi kimia dan fisik. ${ }^{7}$ Glass fiber merupakan serat penguat yang paling sering digunakan. Keuntungan dari glass fiber adalah kekuatan, transparansi, dan harga yang relatif murah. ${ }^{8}$ Bahan glass fiber dengan struktur yang searah memiliki kekuatan dan kelenturan dua kali lebih kuat dari bahan polyethylene fiber, namun glass fiber memiliki kekakuan yang kurang baik dan sering menunjukkan keretakan di permukaan. ${ }^{9}$ Setiap bahan fiber memiliki kelebihan dan kekurangan, sehingga perlu diperhatikan sifat fisik bahan fiber yang ditambahkan pada plat gigi tiruan diantaranya adalah jenis fiber dan rasio fiber/matriks. Penentuan sifat fisik serta jumlah (volume) fiber yang tepat dalam resin akrilik mampu menghasilkan kekuatan yang lebih baik pada plat gigi tiruan resin akrilik. ${ }^{10}$ Fiber yang ditempatkan secara benar dalam jumlah tepat dapat meningkatkan kekuatan gigi tiruan. ${ }^{11}$

Uji transversal merupakan simulasi distribusi tekanan yang diterima plat gigi tiruan di dalam rongga mulut. Kekuatan transversal yang tinggi dibutuhkan suatu material untuk tahan terhadap tekanan pengunyahan yang dapat mengakibatkan deformasi permanen. ${ }^{12}$ Penelitian ini dilakukan dengan tujuan mengetahui pengaruh jenis dan volumetrik fiber terhadap kekuatan transversal reparasi plat resin akrilik. Penelitian ini telah mendapatkan kelaikan etik penelitian (ethical clearance) dari Unit Etika dan Advokasi FKG UGM nomor 722/KKEP/FKG-UGM/EC/2014.

\section{METODE PENELITIAN}

Sampel akrilik berbentuk persegi panjang ukuran $65 \times 10 \times 2,5 \mathrm{~mm}$ dengan modifikasi kavitas pada bagian tengahnya berukuran $30 \times 5$ x $2 \mathrm{~mm}$ dibuat dari cetakan logam dengan bentuk (sesuai dengan sampel) yang ditanam dalam kuvet berisi adonan gips plaster, setelah gips mengeras kemudian diolesi dengan vaselin dan dibuat kontra model. Cetakan logam diambil setelah kontra model mengeras sehingga terbentuk ruang cetakan (mould). Mould yang terbentuk dan kontra model diolesi dengan CMS agar resin tidak melekat pada gips. Monomer dan polimer resin akrilik dicampur dalam stellon pot dengan perbandingan sesuai ketentuan pabrik, yaitu 23 gram polimer dan 10 $\mathrm{ml}$ monomer. Adonan resin akrilik dimasukkan ke dalam cetakan setelah mencapai fase dough. Kuvet di-press hingga metal to metal contact dan dibiarkan 1 jam agar stabilitas dimensi lebih baik. ${ }^{12}$

Kuvet beserta press diproses dalam air bersuhu $70^{\circ} \mathrm{C}$ selama 90 menit kemudian suhu dinaikkan sampai $100^{\circ} \mathrm{C}$ selama 30 menit. Setelah prosesing selesai, kuvet dibiarkan sampai mencapai suhu kamar. Plat resin akrilik diambil dan dihaluskan dengan amplas no 300 , 600, dan 1000 kemudian diukur dengan sliding caliper. Subjek penelitian dibuat 25 buah untuk 5 kelompok perlakuan. Masing-masing batang uji dibagi menjadi 2 sama panjang dan diberi tanda dengan menggunakan pensil. Batang uji dipotong menggunakan carborundum disc dan dibuat jarak $3 \mathrm{~mm}$ pada tepi preparasi (batang uji yang telah terpotong menjadi 2 dikurangi masing-masing 1,5 $\mathrm{mm}$ pada tepi preparasi). Pada tepi preparasi dibuat sudut kemiringan $45^{\circ}$ untuk menambah retensi reparasi. Batang uji yang telah siap disambung diletakkan ke dalam mould yang telah disiapkan berukuran $65 \times 10 \times 2,5 \mathrm{~mm}$. 
Untuk menghitung fraksi volumetrik fiber dalam plat resin akrilik yaitu dengan membandingkan volume fiber dengan volume sampel plat resin akrilik. Fraksi volumetrik untuk 5 lembar polyethylene fiber [(vol. 5 lembar polyethylene fiber /vol. Sampel) $\times 100 \%=(60 / 1625) \times 100 \%=3,7 \% \mathrm{v} / \mathrm{v}]$, fraksi volumetrik untuk 10 lembar polyethylene fiber [(vol. 10 lembar polyethylene fiber /vol. Sampel) x 100\% $=(120 / 1625) \times 100 \%=7,4 \% \mathrm{v} / \mathrm{v}]$, fraksi volumetrik untuk 1 bundel E-glass fiber [(vol. 1 bundel E-glass fiber/vol. Sampel) $\times 100 \%=(60 / 1625) \times 100 \%=$ $3,7 \% \mathrm{v} / \mathrm{v}]$, fraksi volumetrik untuk 2 bundel E-glass fiber [(vol. 2 bundel E-glass fiber/vol. Sampel) $\mathrm{x}$ $100 \%=(120 / 1625) \times 100 \%=7,4 \% \mathrm{v} / \mathrm{v}]$.

Subjek penelitian dibagi menjadi 5 kelompok, masing-masing kelompok berjumlah 5 batang uji resin akrilik. Kelompok I: kontrol, plat resin akrilik polimerisasi panas direparasi dengan resin akrilik baru (polimerisasi panas) tanpa fiber. Kelompok II: plat resin akrilik polimerisasi panas direparasi dengan menempatkan $3,7 \% \mathrm{v} / \mathrm{v}$ fraksi volumetrik polyethylene fiber pada mould preparasi dilanjutkan aplikasi resin akrilik baru (polimerisasi panas). Kelompok III: plat resin akrilik polimerisasi panas direparasi dengan menempatkan $7,4 \% \mathrm{v} / \mathrm{v}$ fraksi volumetrik polyethylene fiber pada mould preparasi dilanjutkan aplikasi resin akrilik baru (polimerisasi panas). Kelompok IV: plat resin akrilik polimerisasi panas direparasi dengan menempatkan $3,7 \% \mathrm{v} / \mathrm{v}$ fraksi volumetrik E-glass fiber pada mould preparasi dilanjutkan aplikasi resin akrilik baru (polimerisasi panas). Kelompok V: plat resin akrilik polimerisasi panas direparasi dengan menempatkan $7,4 \% \mathrm{v} / \mathrm{v}$ fraksi volumetrik E-glass fiber pada mould preparasi dilanjutkan aplikasi resin akrilik baru (polimerisasi panas).

Pembuatan adonan resin akrilik polimerisasi panas dengan perbandingan antara monomer dan polimer adalah $1 \mathrm{cc}$ : 2,3 g. Pada kelompok I (kontrol tanpa fiber), adonan yang telah mencapai fase dough langsung ditempatkan pada mould preparasi, kontra model ditutupkan dan dilakukan pengepresan. Kuvet beserta alat press direbus ke dalam air bersuhu $100^{\circ} \mathrm{C}$ selama 45 menit, setelah itu ditunggu hingga air menjadi dingin dalam suhu kamar kemudian batang uji yang telah direparasi diambil, dirapikan eksesnya, dipoles. Pada kelompok II sebelum penempatan adonan resin akrilik terlebih dahulu diberikan bahan 5 lembar polyethylene fiber yang telah diberi selapis tipis adonan resin akrilik untuk menyatukan tiap lembar fiber kemudian ke dalam mould preparasi. Adonan resin akrilik yang telah mencapai fase dough ditempatkan pada mould preparasi, kontra model ditutupkan dan dilakukan pengepresan. Kuvet beserta alat press direbus ke dalam air bersuhu $100^{\circ} \mathrm{C}$ selama 45 menit, setelah itu ditunggu hingga air menjadi dingin dalam suhu kamar kemudian batang uji yang telah direparasi diambil, dirapikan eksesnya, dipoles. Pada kelompok III sebelum penempatan adonan resin akrilik terlebih dahulu diberikan bahan 10 lembar polyethylene fiber (2 susunan bersebelahan masing-masing susunan terdiri dari 5 lembar fiber) yang telah diberi selapis tipis adonan resin akrilik untuk menyatukan tiap lembar fiber kemudian ke dalam mould preparasi. Adonan resin akrilik yang telah mencapai fase dough ditempatkan pada mould preparasi, kontra model ditutupkan dan dilakukan pengepresan. Kuvet beserta alat press direbus ke dalam air bersuhu $100^{\circ} \mathrm{C}$ selama 45 menit, setelah itu ditunggu hingga air menjadi dingin dalam suhu kamar kemudian batang uji yang telah direparasi diambil, dirapikan eksesnya, dipoles. Pada kelompok IV sebelum penempatan adonan resin akrilik terlebih dahulu diberikan bahan 1 bundel E-glass fiber ke dalam mould preparasi. Adonan resin akrilik yang telah mencapai fase dough ditempatkan pada mould preparasi, kontra model ditutupkan dan dilakukan pengepresan. Kuvet beserta alat press direbus ke dalam air bersuhu $100^{\circ} \mathrm{C}$ selama 45 menit, setelah itu ditunggu hingga air menjadi dingin dalam suhu kamar kemudian batang uji yang telah direparasi diambil, dirapikan eksesnya, dipoles. Pada kelompok $\mathrm{V}$ sebelum penempatan adonan resin akrilik terlebih dahulu diberikan bahan 2 bundel E-glass fiber yang disusun bersebelahan ke dalam mould preparasi. Adonan resin akrilik yang telah mencapai fase dough ditempatkan pada mould preparasi, kontra model ditutupkan dan dilakukan pengepresan. Kuvet beserta alat press direbus ke dalam air bersuhu $100^{\circ} \mathrm{C}$ selama 45 menit, setelah itu ditunggu hingga air menjadi dingin dalam suhu 
kamar kemudian batang uji yang telah direparasi diambil, dirapikan eksesnya, dipoles. Sebelum dilakukan uji kekuatan mekanik, sampel disimpan dalam inkubator dengan direndam di aquadest pada suhu $37^{\circ} \mathrm{C}$ selama 24 jam. Perendaman ini bertujuan untuk memperoleh kondisi yang sama dengan kondisi oral dan equilibrium water sorption. ${ }^{13}$ Uji kekuatan trasversal dikerjakan dengan alat universal testing machine. dan seiring dengan penambahan volumetrik fiber (lihat Tabel 1).

Hasil uji normalitas menggunakan ShapiroWilk menunjukkan nilai statistik $0,92(p=0,15)$. Uji homogenitas data kekuatan transversal dilakukan menggunakan Levene's Test. Hasil uji homogenitas menunjukkan nilai statistik 2,91 $(p=0,067)$. Pada uji ANAVA 2 jalur menunjukkan

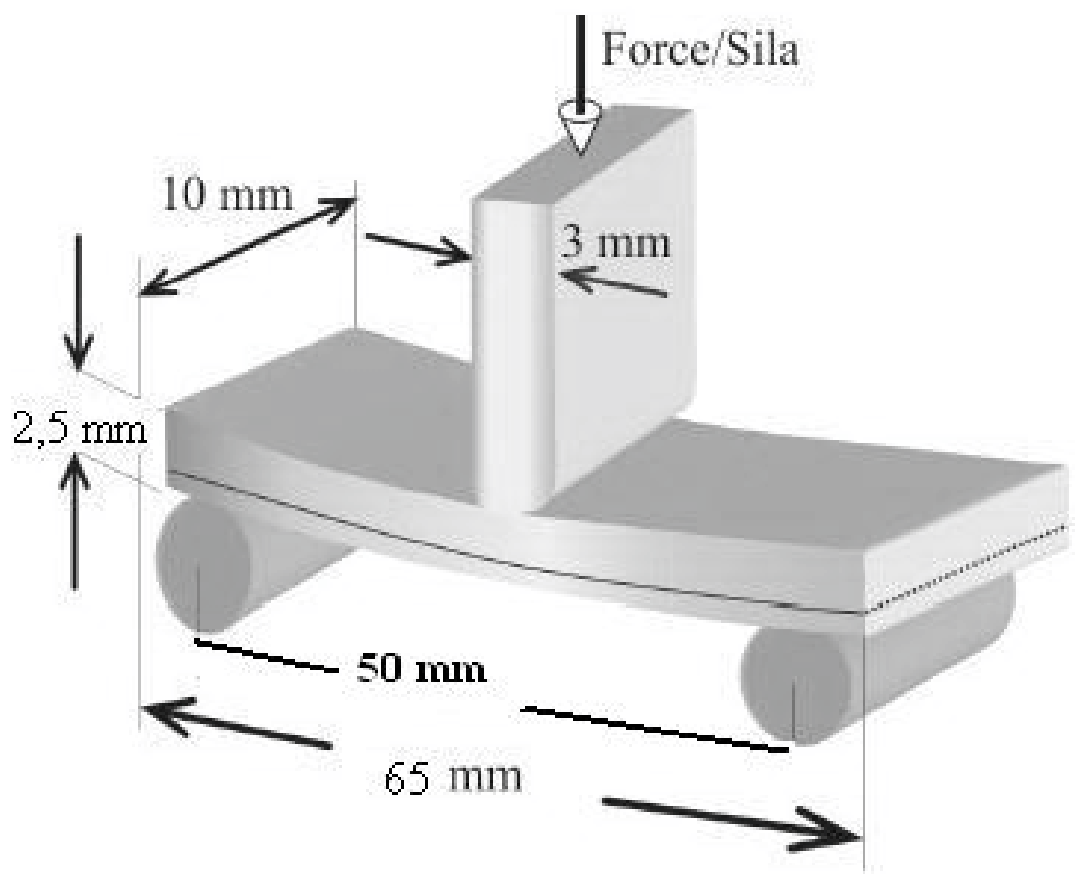

Gambar 1. Skema Simulasi pengukuran kekuatan transversal pada batang uji

\section{HASIL PENELITIAN}

Penelitian diawali dengan pembuatan sampel di Laboratorium Riset Terpadu FKG UGM kemudian dilanjutkan dengan pengujian kekuatan transversal di Laboratorium Bahan Teknik Mesin dan Industri Fakultas Teknik UGM. Pengujian kekuatan transversal terhadap sampel menunjukkan jika plat resin akrilik yang direparasi dengan penambahan E-glass fiber dengan volumetrik 7,4\% $\mathrm{v} / \mathrm{v}$ menghasilkan kekuatan transversal tertinggi dibandingkan kelompok subjek penelitian yang lain. Secara umum, rerata kekuatan transversal pada semua kelompok dengan variabel jenis dan volumetrik memperlihatkan adanya kecenderungan peningkatan kekuatan transversal. Peningkatan terjadi dari jenis polyethylene fiber ke E-glass fiber, nilai $F$ untuk variabel jenis fiber sebesar 123,39 dan untuk variabel volumetrik fiber sebesar 23,5 dengan masing-masing menunjukkan signifikansi $(p<0,05)$. Berdasarkan hal tersebut dapat disimpulkan bahwa variasi jenis dan volumetrik fiber memiliki pengaruh bermakna terhadap kekuatan transversal reparasi plat resin akrilik. Interaksi antara variabel jenis dengan variabel volumetrik fiber menunjukkan pengaruh tidak bermakna $(p>0,05)$ terhadap kekuatan transversal (lihat Tabel 2).

Hasil analisis post hoc Tukey untuk seluruh kelompok dengan variasi jenis dan volumetrik menunjukkan terdapat perbedaan bermakna antara kekuatan transversal dalam seluruh kelompok perlakuan $(p<0,05)$ (lihat Tabel 3). 
Tabel 1. Rerata dan standar deviasi kekuatan transversal (MPa) reparasi plat resin akrilik yang diperkuat fiber dengan jenis dan volumetrik yang berbeda

\begin{tabular}{lrcc}
\hline \multicolumn{1}{c}{ Kelompok } & N & Rerata & Standar Deviasi \\
\hline Akrilik reinforced 3,7\% v/v polyethylene fiber & 5 & 67,77 & 3,34 \\
Akrilik reinforced 7,4\% v/v polyethylene fiber & 5 & 80,37 & 8,42 \\
Akrilik reinforced 3,7\% v/v E-glass fiber & 5 & 96,72 & 5,43 \\
Akrilik reinforced 7,4\% v/v E-glass fiber & 5 & 109,44 & 4,98 \\
Akrilik tanpa fiber & 5 & 56,27 & 4,70 \\
\hline
\end{tabular}

Tabel 2. Rangkuman hasil statistik two way ANOVA kekuatan transversal reparasi plat resin akrilik yang diperkuat fiber dengan variabel jenis dan volumetrik

\begin{tabular}{|c|c|c|c|}
\hline Variabel & $\mathrm{db}$ & $\mathrm{F}$ & $p$ \\
\hline Jenis & 1 & 123,93 & 0,00 \\
\hline Volumetrik & 1 & 23,50 & 0,00 \\
\hline Interaksi jenis-volume & 1 & 0,001 & 0,98 \\
\hline
\end{tabular}

Tabel 3. Rangkuman uji Tukey kekuatan transversal reparasi plat resin akrilik yang diperkuat fiber dengan variabel jenis dan volumetrik

\begin{tabular}{|c|c|c|c|c|c|}
\hline Kelompok & $\begin{array}{c}3,7 \% \mathrm{v} / \mathrm{v} \\
\mathrm{PE}\end{array}$ & $\begin{array}{c}7,4 \% \mathrm{v} / \mathrm{v} \\
\mathrm{PE}\end{array}$ & $\begin{array}{l}3,7 \% \mathrm{v} / \mathrm{v} \\
\text { E-glass }\end{array}$ & $\begin{array}{l}7,4 \% \mathrm{v} / \mathrm{v} \\
\text { E-glass }\end{array}$ & $\begin{array}{c}\text { Tanpa } \\
\text { fiber }\end{array}$ \\
\hline $3,7 \%$ v/v PE & & $-12,60^{*}$ & $-28,94^{*}$ & $-41,66^{*}$ & $11,51^{*}$ \\
\hline $7,4 \%$ v/v PE & & & $-16,34^{*}$ & $-29,06^{*}$ & $24,11^{*}$ \\
\hline $3,7 \%$ v/v E-glass & & & & $-12,72^{*}$ & $40,45^{*}$ \\
\hline 7,4\% v/v E-glass & & & & & $53,17^{*}$ \\
\hline Tanpa fiber & & & & & \\
\hline
\end{tabular}

$*$ berbeda bermakna $(p<0,05)$

Tabel 1 terlihat adanya perbedaan rerata kekuatan transversal antara plat resin akrilik yang diberikan penguat fiber dengan yang tanpa diperkuat fiber. Hal ini disebabkan karena fiber mampu mengurangi tekanan yang diterima oleh resin akrilik sebagai plat gigi tiruan yang mempunyai kelemahan mudah patah. Bahan fiber memiliki peranan terhadap sifat-sifat mekanik diantaranya adalah memiliki kekuatan impak yang baik. Terdapat beberapa cara untuk meminimalkan tekanan yang dapat mengurangi fraktur suatu material diantaranya dengan mendistribusikan tekanan ke bahan yang memiliki modulus elastisitas yang lebih tinggi. ${ }^{12}$

Pada tabel 1 juga terlihat jika E-glass fiber memiliki rerata kekuatan transversal yang lebih tinggi dari jenis polyethylene fiber. Hal ini dapat disebabkan karena adanya kandungan metal oksida pada E-glass fiber. Metal oksida seperti $\mathrm{SiO}_{2}$ yang berfungsi seperti filler dalam sistem fiber. Kandungan filler dalam suatu sistem material dapat meingkatkan kekuatan mekanik dari suatu material, salah satunya kekuatan transversal. ${ }^{12} \mathrm{Hal}$ ini memperkuat alasan jika E-glass fiber menghasilkan kekuatan transversal yang lebih tinggi dibandingkan polyethylene fiber. Penambahan fiber dengan volumetrik $7,4 \% \mathrm{v} / \mathrm{v}$ menghasilkan kekuatan yang lebih tinggi dibandingkan volumetrik $3,7 \%$ v/v baik pada jenis polyethylene fiber maupun jenis E-glass fiber. Penambahan jumlah fiberselain meningkatnya kekuatan impak juga dapat meningkatkan kekuatan transversal dari resin polimetil metakrilat. ${ }^{14}$ Fraksi volumetrik fiber dapat meningkatkan $65 \%$ kekuatan 
konstruksi gigi tiruan cekat, dari penemuan ini maka dapat dikatakan jika 2 lembar fiber akan memberikan kekuatan transversal yang lebih tinggi dibandingkan 1 lembar fiber..$^{15}$

Tabel 2 menunjukkan, berdasarkan analisis statistik, jenis fiber berbeda secara bermakna dimana fiber jenis E-glass menghasilkan kekuatan transversal yang lebih tinggi pada reparasi plat resin akrilik. Untuk meningkatkan adhesi, dalam penelitian ini dilakukan pengulasan cairan monomer pada permukaan fiber. Pembasahan fiber dapat meningkatkan kekuatan fiber rinforced dan adhesi polimer dengan fiber. Impregnasi cairan monomer pada polyethylene fiber dengan struktur anyaman lebih buruk dibandingkan pada E-glass fiber dengan struktur unidirectional sehingga kekuatan mekanik pada polyethylene fiber dengan struktur anyaman juga lebih rendah. Pada impregnasi cairan monomer yang baik pada fiber, kekuatan transversal dapat tereduksi karena gaya yang muncul dapat diteruskan ke seluruh permukaan matrik dengan baik. ${ }^{16}$

\section{PEMBAHASAN}

Modifikasi permukaan fiber dengan menggunakan silane seperti yang terdapat pada E-glass fiber dapat meningkatkan adhesi antara fiber dan polimer sehingga dapat meningkatkan kekuatan mekanik dari fiber reinforced. ${ }^{16}$ Penggunaan silane coupling agent mengakibatkan E-glass fiber mampu berikatan dengan matriks resin akrilik. Silane memiliki gugus hidroksi yang dapat tertarik ke dalam gugus hidoksi pada permukaan E-glass fiber. Gugus organo-functional bereaksi dengan matriks resin dan membentuk ikatan yang kuat. Silane dapat berikatan dengan resin polymethyl methacrylate. Silane terhidrolisis menjadi silanol dan membentuk ikatan kovalen pada gugus $\mathrm{CH}_{2}$ methyl methacrylate. Silanol dapat membentuk ikatan kovalen dengan rantai polimer resin dan membentuk gugus organik. ${ }^{17}$

Penambahan fiber dengan volumetrik 7,4\% $\mathrm{v} / \mathrm{v}$ menghasilkan kekuatan transversal yang lebih tinggi. Pada benda homogen, penambahan volumetrik fiber akan menambah kemampuan mendistribusi tekanan dan menghasilkan resultan gaya yang lebih kecil karena penyerapan tekanan yang lebih banyak. Pada penambahan fiber tekanan yang dihasilkan akan kecil sehingga mengakibatkan timbulnya kemampuan menahan perubahan bentuk yang berakibat fraktur. ${ }^{18}$ Kekuatan dari fiber reinforced composite (FRC) dipengaruhi oleh volume fiber, kekuatan fiber, volume polimer matrik, dan kekuatan polimer matrik, sehingga kekuatan transversal akan berbanding lurus dengan volume fiber dengan ketentuan bentuk dan ukuran yang sama. ${ }^{19} \mathrm{Hal}$ ini menunjukkan bahwa kekuatan transversal dipengaruhi oleh volumetrik fiber.

Analisis post hoc menunjukkan bahwa seluruh kelompok perlakuan berbeda secara bermakna $(p<0,05)$. Plat resin akrilik tanpa fiber menunjukkan rerata paling rendah dibandingkan kelompok dengan penambahan fiber. Hal ini dikarenakan bahan fiber memiliki modulus elatisitas yang lebih tinggi sehingga lebih tahan terhadap tekanan dibandingkan dengan kelompok tanpa penguat fiber. Tekanan yang diterima plat resin terbagi oleh polimer dan fiber. Ellakwa dkk., pada tahun 2002 telah mengevaluasi pengaruh berbagai jenis fiber terhadap kekuatan transversal bahan resin, seluruh kelompok kontrol tanpa fiber menunjukkan kekuatan transversal yang lebih rendah. ${ }^{18}$

Pada penelitian ini terlihat jika plat resin akrilik yang direparasi tanpa tambahan fiber menghasilkan rerata kekuatan transversal di bawah $60 \mathrm{MPa}$. Kekuatan transversal yang harus dimiliki oleh bahan resin akrilik sebagai plat gigi tiruan dalam rongga mulut minimal adalah 60-65 $\mathrm{Mpa},{ }^{12}$ sehingga penambahan fiber dalam reparasi plat resin akrilik dapat dijadikan pilihan. Kekuatan yang lebih tinggi dari standar minimal plat resin akrilik diperlukan karena kekuatan gigitan pada gigi anterior manusia dapat mencapai $132,748 \mathrm{MPa}$, sedangkan pada gigi posterior mencapai 237,169 $\mathrm{Mpa},{ }^{20}$ sehingga penentuan jenis dan volumetrik fiber sebagai bahan penguat reparasi plat resin akrilik diperlukan untuk meningkatkan kekuatan mekanik dari plat resin akrilik.

\section{KESIMPULAN}

Terdapat pengaruh jenis fiber terhadap kekuatan transversal reparasi plat resin akrilik. 
E-glass fiber meningkatkan kekuatan transversal lebih tinggi daripada polyethylene fiber. Terdapat pengaruh volumetrik fiber terhadap kekuatan transversal reparasi plat resin akrilik. Fiber dengan volumetrik $7,4 \%$ v/v dapat meningkatkan kekuatan transversal reparasi plat resin akrilik lebih tinggi dibandingkan volumetrik $3,7 \% \mathrm{v} / \mathrm{v}$ baik pada jenis polyethylene fiber maupun jenis E-glass fiber.

\section{UCAPAN TERIMAKASIH}

Penelitian ini didanai oleh DIKTI melalui dana Beasiswa Unggulan tahun 2012.

\section{DAFTAR PUSTAKA}

1. Agtini MD. Persentase Pengguna Protesa di Indonesia. Media Litbang Kesehatan. 2010; 10(2): 50-58.

2. Nirwana I. Kekuatan Transversal Resin Akrilik Hybrid Setelah Penambahan Glass Fiber dengan Metode Berbeda. Dental Jurnal. 2005; 38(1).

3. El-Sheikh AM dan Al-Zahrani SB. Causes of Denture Fracture: A Survey. Saudi Dental Journal. 2006; 18(3): 149-154.

4. Colvenkar SS dan Aras MA. In Vitro Evaluation of Transverse Strength of Repair Heat Cured Denture Base Resins With and Without Surface Chemical Treatment. J Indian Prosthet Dent. 2008; 8(2): 87-93.

5. Jubhari EH. Penggunaan Jaring Penguat Sambungan untuk Memperbaiki Kekuatan Hasil Reparasi Lempeng Akrilik. 2003. Diakses dari http://www.pdgi-online.com. Diunduh 14 September 2013. 2008.

6. Mallick PK. Fiber Reinforced Composite: Material, Manufacturing, and Design. $3^{\text {rd }}$ ed. France: CRC Press; 2008.

7. Junior AAG, Lopes MWV, Gaspar GS, dan Braz R. Comparative Study of Flexural Strength and Elasticity Modulus in Two Type of Direct Fiber-Reinforced System. Braz Oral Res. 2009; 23(3): 236-240.

8. Le Bell-Rönnlöf dan Anna-Maria. Fiber Reinforced Composites as Root Canal Posts. Turku Finland: 2007.
9. Van Heumen C. Fiber Reinforced Adhesive Bridges Clinical and Laboratory Performance. Thesis. Dutch: Radboud University Nijmegen. 2010. H.11-50.

10. Febriani M. Pengaruh Penambahan Serat pada Basis Gigi Tiruan Resin Akrilik. Jurnal IImiah dan Teknologi Kedokteran Gigi. FKG UPDM(B). 2003; 129-132.

11. Narva KK, Lassila LVJ, dan Vallittu PK. The Static Strength and Modulus of Fiber Reinforced Denture Base Polymer. J Dent Mat. 2005; 21:421-428.

12. Anusavice KJ. Buku Ajar IImu Bahan Kedokteran Gigi (terj.). 10 $0^{\text {th }}$ ed. Jakarta: EGC. 2004. H.98-99.

13. Power JM, Sakaguchi RL. Craig's Restorative Dental Materials. $12^{\text {th }}$ ed. St. Louis: Elsevier. 2006. H.524.

14. Chen S, Liang W, dan Yen P. Reinforced of Acrylic Denture Base Resin by Incorporation of Various Fibers. Journal of Biomedical Material Research. 2001; 58(2): 203-208.

15. Callaghan DJ, Vaziri A, dan Nayeb-Hashemi H. Dental Material. 2006. H.84-93.

16. Vallittu PK. Interpenetrating polymer networks (IPNs) in Dental Polymers and Composite. J Adhes Sci Technol. 2009; 23(7-8): 961-972.

17. Van Noort. Introduction to Dental Materials. $3^{\text {rd }}$ ed. St.Louis: Mosby Company; 2007.

18. Ellakawa $A E$, Shortall AC, dan Marquis PM. Influence of different techniques of laboratory construction on the fracture resistance of fiber reinforced composite bridges. J Contemp Dent Prac. 2004; (5)4: 1-13.

19. Alander P, Lassila LV, dan Vallittu PK. The Span Length and Cross-sectional design affect values of Strength. Dent Mater. 2005; 21: 347-353.

20. Houston TE. Bite Force and Bite Pressure: Comparasion of Human and Dogs. 2003. Diakses dari http://www.glapbta.com/BFBP. pdf. Diunduh 1 November 2014 